\title{
Conducting Research in a Post-normal Paradigm: Practical Guidance for Applying Co-production of Knowledge
}

\author{
Leticia Antunes Nogueira*, Maiken Bjørkan and Brigt Dale \\ Environment and Society Group, Nordland Research Institute, Bodø, Norway
}

Meaningful engagement between scientists and stakeholders has been extensively promoted as a tool for increasing public participation in science, as well as for increasing the relevance and impact of scientific research. Yet, co-production of knowledge entails practical challenges, since participants with diverse worldviews, expertise and interests are expected to collaborate. These obstacles have not received enough attention, as current debate has focused more on the merits and principles of this approach. We address this gap by reflecting upon our experiences with both practical and

OPEN ACCESS

Edited by:

Scott McWilliams,

University of Rhode Island,

United States

Reviewed by:

Chrisna Du Plessis,

University of Pretoria, South Africa

Richard Stoffle,

University of Arizona, United States

${ }^{*}$ Correspondence: Leticia Antunes Nogueira lan@nforsk.no

Specialty section: This article was submitted to

Science and Environmental Communication,

a section of the journal Frontiers in Environmental Science

Received: 23 April 2021

Accepted: 29 July 2021

Published: 10 August 2021

Citation:

Nogueira LA, Bjørkan $M$ and Dale $B$ (2021) Conducting Research in a Postnormal Paradigm: Practical Guidance for Applying Co-production of Knowledge.

Front. Environ. Sci. 9:699397. doi: 10.3389/fenvs.2021.699397 methodological challenges stemming from research projects based on co-production of knowledge, thereby exposing what we see as common but under-discussed obstacles, as well as guidance for tackling them. We highlight the role of social scientists in the process not merely as facilitators but also as agents that promote critical reflection and safeguard the salience, credibility, and legitimacy of both the process and its outputs.

Keywords: co-production of knowledge, post-normal science, experience-based knowledge, science-practice interface, transdisciplinary research projects, science technology and innovation

\section{INTRODUCTION}

Science and technology have long been promoted as central tools for addressing all sorts of challenges, from the threats of climate change and overconsumption to the perils of food scarcity (European Commission, 2013; Üzelgün and Pereira, 2020). More ambitiously, science and technology are often placed prominently in our conceptions of a good society (e.g., Brey, 2018), despite growing recognition that there can be a dark side to innovation (Nogueira and Nogueira, 2015; Coad et al., 2020). Hence, enthusiasm for science and optimism for innovation currently coexist with misinformation and skepticism towards experts. To counteract the effects of this polarization, civil society and policymakers expect scientists not only to justify the relevance and usefulness of their pursuits, but also to anticipate the impacts of their work (Rau et al., 2018). Arguing for impact also grounds the scientific enterprise in a broader set of stakeholder interests (Rodríguez et al., 2013), and legitimizes the public value of research (McNie et al., 2016). These shifts in the social contract between science and society have demanded that collaborative methods are adopted more widely (Chopyak and Levesque, 2002; Wildschut, 2017).

As a result, co-production of knowledge has emerged from the recognition that science and society are intertwined (Jasanoff, 2004), and hence the process of research and its resulting scientific knowledge do not merely depict and describe the world "as is" (Williams and Edge, 1996). Instead, the communion between the physical and the social worlds is an inherent characteristic of knowledge 
production (Funtowicz and Ravetz, 1993; Ravetz, 1999; Jasanoff, 2004). Science (i.e., "fact") cannot be neatly separated from the influence of the socio-political world (i.e., "values"), and the "post-normal problems" of our time increasingly challenge the notion of scientific purity (Jasanoff et al., 1995; Farrell, 2011). The social world shapes decisions concerning which problems are investigated and how they are researched, i.e., the angles from which phenomena are observed, the premises that are adopted, and the processes of allocating funds. We can identify a problem as "post-normal" when it is characterized by high complexity and uncertainty, is riddled with conflict of values, and, at the same time, challenges established legitimacy. The process of solving such problems rarely yields single answers, if any at all (Funtowicz and Ravetz, 1993; Ravetz and Funtowicz, 1999). In fact, living in the post-normal world increasingly requires living with-and planning through-contingencies (Foucault, 2008). Arguably, recognizing the ways in which science, technology, and society interface "is one of the most pressing issues of the 21st century" (Chopyak and Levesque, 2002). Co-production of knowledge is a fitting approach in such landscape.

In line with Norström et al., we define co-production of knowledge as "iterative and collaborative processes involving diverse types of expertise, knowledge and actors to produce context-specific knowledge" (Norström et al., 2020, p. 5). Although there is abundant and long-standing literature on the topic, particularly stemming from Science and Technology Studies (which is in turn heavily influenced by a century of anthropological research), collaborative processes require practical skills about the challenges that arise in such transdisciplinary and collaborative contexts (Polk, 2015; Dankel et al., 2017). The current landscape of policy and funding for science and technology mean that knowledge is often produced on demand and with the intent to address a specific problem of immediate consequence (Boswell and Smith, 2017). As such, scientific advancement as a purely intellectual pursuit motivated mainly by curiosity all but ceases to exist. The implication for scientists-the majority of whom are trained to overlook the social embeddedness of their activities-is that they strive to balance what they perceive as the nobility of the scientific enterprise ("the ideal") with utilitarian interests and practical concerns ("the real"). Addressing gaps concerning how to operationalize co-production research is of utmost importance as this approach becomes institutionalized (Lemos et al., 2018). It is not sufficient to merely put people together in a room. Constructive results depend on researchers addressing colliding worldviews, worries, vocabularies and interests. Yet, there is little knowledge and even less guidance on how to go about this task.

Hence, the purpose of this paper is to address this need for guidance for co-production of knowledge. In putting forth our recommendations, we rely upon our applied experiences examining a broad array of themes, industries, and sectors. These range from the management of fish resources, marine plastics, and petroleum exploration in the Arctic to the overarching challenge of climate change (Kristoffersen and Dale, 2014; Dale, 2016; Rybråten et al., 2018; Johnsen et al., 2019a; Johnsen et al., 2019b; Bjørkan and Veland, 2019; Dale et al., 2019; Röhrs et al., 2020; Strand et al., 2021). Our ambition is to reflect upon these experiences and illuminate what we view as typical challenges that come about when implementing "principles for knowledge co-production" (Norström et al., 2020). We focus predominantly on the dynamic that emerges when science embraces diverse types of experts ${ }^{1}$, who then become present in spaces that had been restricted to them until post-normal problems began to challenge traditional boundaries between experts and lay-people.

The following section discusses co-production of knowledge as a hands-on method that is relevant to different schools of thought on why co-production matters. Additionally, it situates coproduction of knowledge in relation to other types of stakeholder participation. We will offer our suggestions for executing research projects based on this approach, and subsequently discuss what role the social sciences can play in such processes.

\section{CONTEXTUALIZING CO-PRODUCTION OF KNOWLEDGE \\ Co-Production Within the Post-normal Paradigm}

The dynamics of post-normal times entail that facts are uncertain, legitimacy and credibility are disputed, and solutions might be ambiguous (Funtowicz and Ravetz, 1993; Ravetz, 1999; Jasanoff and Simmet, 2017). Technology is, in this context, both a concrete and politicized tool for human agency and an abstract and exogenous force that shapes social relations (Üzelgün and Pereira, 2020). Such context is, at once, an emergent empirical phenomenon, and a normative prescription on how science should be carried out. We explore below the differences between these two perspectives.

Portraying post-normality as an emergent empirical phenomenon requires recognizing that the conflation of facts and values does happen in research, whether or not people are cognizant of it, and despite their best intentions to keep these separate (Williams and Edge, 1996). In particular, as knowledge production has become more industrialized and disciplines more specialized, there have been dramatic changes in the relationships between scientists, their peers, and the actors who judge and use the output of scientific work (e.g., funders and policymakers). These changes have driven the merging of facts and values further (Ravetz, 1971; Skolnikoff, 2001; McNie et al., 2016). Moreover, lay-people are becoming ever more knowledgeable and trained in scientific methods and now have unprecedented access to resources for data collection and small-scale experiments (Chopyak and Levesque, 2002; Wildschut, 2017). In

\footnotetext{
${ }^{1}$ We note a nuanced distinction between science-driven and context-driven initiatives. In the first, which is our focus, the driving force is the long-standing scientific ambition to advance knowledge; in the latter, more tangible and immediate interventions are the central drivers. Context-driven initiatives have some overlap with the field of user-driven innovation (Hippel, 2006), which is in itself a large body of literature and falls outside the scope of this paper.
} 
Scandinavia, for example, anyone can register their observations of bears, wolves, and other predators in an app (i.e., Rovdata and Naturvårdsverket, 2021), which is used for monitoring and research purposes; likewise, fishers in Norway are routinely involved in the gathering of scientific data for assessment of fish stocks (Bjørkan, 2011). This competence is also spreading through the developing world, as internet connection and smartphones become ubiquitous (e.g., Liebenberg et al., 2017).

Some challenges arise under this expanding empirical reality, such as how decision-makers design policies (and how scientists carry out their work) when hard facts become "soft", and "fluffy" values become solid (Funtowicz and Ravetz, 1993; Jasanoff, 2004). Such questions do carry normative implications, but these are based on acknowledging that attempts to neatly categorize findings into the domains of either value or fact are dissonant with the reality of science in practice (Latour, 1987; Farrell, 2011; Rau et al., 2018).

Another perspective portrays post-normal science in normative terms - that is, it prescribes that science is supposed to be carried out in close connection with diverse social actors (Saltelli and Funtowicz, 2017). Such perspective can be traced to the 1990s, when political theorists began to consider that there was a wider role for citizens in a democracy, beyond that of expressing preferences through votes; that is, public deliberation should precede the vote and inform decision-making (Poblet et al., 2019). This became known as the deliberative turn in democracy theory of the 1990s (Dryzek and Braithwaite, 2000; Lövbrand et al., 2011), and it builds upon the notion of social justice. As such, the deliberative turn advocates for the democratization of knowledge and expertise, not only regarding who consumes it, but also who produces it. Research is then seen as a space for presenting evidence and for mutual learning in which various types of knowledge and ways of knowing are accepted (Turnpenny et al., 2011). A normative viewpoint on post-normal science extends the boundaries of traditional science, and places greater emphasis on relevance than on truth (Funtowicz and Ravetz, 1993).

Because of its strong foothold in public engagement, science under the post-normal perspective tends to be more issue-driven than curiosity-driven. This shift has been embraced by large funders of scientific research, such as the European Framework Program for Research and Innovation, and made apparent by the growing demands for projects to adopt a multiactor approach and adhere to the principles of Responsible Research and Innovation (European Commission, 2014), as well as to co-design activities with stakeholders (European Commission, 2021). One crucial concern in this regard is the potential for normative standards to become merely bureaucratic requirements (Lemos et al., 2018) or performative discourses (Owen et al., 2021). Or worse, that public engagement becomes a rhetorical device for legitimacy, and means to further prevalent worldviews and practices. Ideally, normalization of engaged scholarship (Van de Ven, 2007) would promote substantial exchanges across various types of stakeholders with diverse interests and expertise in the pursuit of knowledge.

While there are differences between post-normal science as an empirical phenomenon and as a normative prescription, both perspectives give rise to the need for a hands-on method-whether the point is to deal with the way the relationship between science and politics is, or to facilitate how society would like it to be (Turnpenny et al., 2011; Kønig et al., 2017). Such method must address the blurred lines between the social world as it is lived and the natural world as it is observed. This method must not obscure the constructed nature of scientific knowledge, rather, it should maintain, or even strengthen, scientific integrity. Moreover, such method can serve the purpose of expanding and increasing public participation in science (Latour, 2004; Lövbrand, 2011; Scherhaufer, 2021), while recognizing science as culture (Latour, 1987), as well as encouraging a broadened and deepened understanding of what constitutes knowledge. Thus, co-production of knowledge (Jasanoff, 2004), aided by the concept of extended peer-community (Funtowicz and Ravetz, 1993; Ravetz, 1999), emerges as a methodological approach that is fit for descriptive/empirical and ethical/normative ambitions.

As a method, co-production of knowledge aims to escape the confines of tradition and linearity, in which complexity is reduced to problems that are researchable through usual methods, within traditional disciplinary domains and communicated to policymakers in a value-free language. Indeed, in many instances, statistical and quantitative methods and models are useful tools for controlling uncertainty. Other issues, however, are exceptionally complex, and uncertainty in these instances may become uncontrollable (Funtowicz and Ravetz, 1993; Strand and Oughton, 2009; Bjørkan and Hiis Hauge, 2019). The latter instances are the situations of interest in this paper, which we exemplify next, before discussing different forms of obtaining knowledge.

\section{Marine Litter as an Exemplary Post-normal Problem}

The case of marine litter embodies the type of systemically intricate circumstances that characterize post-normality. Plastic pollution is of particular concern, since plastic not only takes several hundred years to decompose, but its presence is now also ubiquitous and irreversible (Villarrubia-Gómez et al., 2018). Besides the visually offending plastic litter on shorelines and in the sea itself, micro-plastics have also been documented in ecosystems as remote as the Alps and the ice-covered Arctic (Bergmann et al., 2019). An empty water bottle collected on an Arctic beach could have been discharged into the sea elsewhere in the world and brought there by ocean currents. Thus, as plastic litter travels long distances and respects no socio-political boundaries, it defies our organizational arrangements in ways that also challenge how we produce knowledge to combat it (Haward, 2018). Likewise, the impacts of pollution are manifold. In addition to the noticeable disruptions to marine life and ecosystems, marine plastic pollution also impacts human health, the quality and availability of fish biomass, as well as economic activities such as fisheries (e.g., ghost fishing from fish nets abandoned at sea), shipping (e.g., propeller fouling) and tourism (e.g., littered beaches) (Derraik, 2002; Bonanno and Orlando-Bonaca, 2018). As a result, addressing the problem of marine litter is a shared responsibility across distinct levels of government from local to international bodies, and any isolated 
policy or measure will reverberate across jurisdictions concerning the environment, society, health, and the economy.

To add to this complexity, there are numerous knowledge gaps concerning not only the amount, trajectory, and fate of plastic particles, but also the effects and toxicity of plastics on humans and ecosystems (Bonanno and Orlando-Bonaca, 2018). In short, marine litter is a problem plagued with uncertainty and highstakes decisions, and it is futile to try to neatly separate which elements reside in fact, and which represent values. When viewed as the ambition to advance knowledge on problems of this nature (as well as advance meaningful action), reductionist approaches and silo thinking are, at best, inadequate. Any measure that fails to account for the problem's systemic nature will fall short of a substantial solution.

\section{Different Forms of Obtaining Knowledge}

Science and Technology Studies illuminate that science is cultural and embedded in social practices. This culture is distinct from others, such as that of policy actors (McNie et al., 2016). Although science aims to produce "a view from nowhere", it is made "somewhere", and in this respect science is like experiencebased knowledge (Latour, 1987). However, the processes through which experience-based knowledge are produced typically lack systematic, formalizing methodologies that are required in the production of scientific knowledge (Holm, 2003; Bjørkan, 2011). Consequently, this knowledge does not fit the frame of formal, authorized knowledge upon which policy management is founded.

In science, there are institutionalized mechanisms for testing, certifying, or dismissing knowledge claims, thereby transforming technical knowledge (technê) into academic knowledge (epistêmê). There are no comparable mechanisms readily available for transforming applied doing/making (praxis and poiêsis) into experience-based knowledge (phronêsis) (Parry, 2020). Hence-while potentially relevant, reliable, and valid-experience-based knowledge is seldom organized in a way that makes the knowledge directly transferable for policy and management purposes (Harrison et al., 2018).

It is important to address that the institutionalized trust in science and its mechanisms typically excludes experience-based knowledge, despite the latter's potential relevance and helpfulness towards the production of knowledge for political or managerial advice, especially in the context of post-normal problems (Saltelli and Giampietro, 2017). Co-production addresses this, since it opens the knowledge production process and brings in various types of knowledge, including that of practice-experts/lay-experts (i.e., non-scientist experts) ${ }^{2}$. Accordingly, co-production should accelerate the diffusion and uptake of the outcome knowledge (Boswell and Smith, 2017), while also adding to the more traditional mechanisms of quality control (Funtowicz and

\footnotetext{
${ }^{2}$ According to Turner, expertise and scientific knowledge differ in that the first "represents the state of knowledge at a particular time, and is not limited to fully developed or tested theories or facts accepted as textbook knowledge by the academic community" (Turner, 2015).
}

Ravetz, 1990) and institutionalizing more democratic participation (Aminpour et al., 2020).

Co-production requires adjustments in the way alternative courses of action are included or excluded in decision-making processes, with the aim of embracing discrepancies, numerous possibilities, and multiple tangible futures (Poli, 2014; AlvialPalavicino, 2016; Granjou et al., 2017). From historic tragedies like Chernobyl to the COVID-19 pandemic, we have seen time and again that the future is highly uncertain and full of potential events that can never be completely predicted by models or forecasts. The need to ensure future resilience and adaptive capacity might just as well be "secured through contingency" (Dale, 2011, p. 60-61) rather than through the familiar process of establishing truth through the "rationalization of chance and probabilities" of scientific assessments (Foucault, 2007, p. 59). To that end, opening up the knowledge production process is particularly relevant. We illustrate this below with an example of the first-hand knowledge of practice-experts.

\section{An Example of Practice-Experts' Knowledge in Early Identification of Post-normal Research Problems}

Practice-experts are in a privileged position to identify research problems and the need for regulation or intervention by governance systems, as well as possible hypotheses and appropriate measures to address those problems. They can also facilitate data collection or be trained to collect data themselves.

One example is a case involving shrimp fishers in Norway, who were the first to observe a decline in shrimp stock and shrimp health around aquaculture sites (Bjørkan and Rybråten, 2019). Their early hypothesis (though not formulated in scientific terminology) was that the shrimp population was harmed by the use of sea lice chemicals in fish farming.

Post-normal dynamics were present at the junction of knowledge gaps, different understandings of the uncertainties involved, and substantial conflicts of interest between shrimp fishers, fish farmers, coastal authorities, and others. Moreover, the problem is related to several wider public debates: the use of common pool resources (in this case, disputes over the use of coastal zones), sustainable food production, the sustainability of fish farming, etc. The issue quickly became polarized.

At first, the hypothesis put forth by the shrimp fishers was dismissed and climate change became one alternative explanation for changes in shrimp health and stocks. Yet notably, this particular case came after a study linked the chemicals in question with shrimp mortality (Busch, 2015). If advisory bodies had adopted precautionary principles, then the use of sea lice agents would have been stopped.

This example (explored in depth in Bjørkan and Rybråten, 2019) also depicts how difficult it is in such cases to separate facts and values in research and decision-making. Thus, it becomes difficult to assess how the socio-political and the natural-scientific are intertwined. It also shows the importance of meaningful interactions between practice-experts, scientists, and advisory bodies, and how co-production of knowledge can support these relationships. 


\section{Degrees of Stakeholder Involvement}

Involving stakeholders in knowledge production entails participation, which is a notion more complex than the everyday use of the term might suggest. A large body of literature highlights that, despite the apparent, generally positive acceptance associated with participation, there is an open debate concerning what it really entails (Rowe and Frewer, 2004; Silver and Campbell, 2005; Bjørkan, 2011). Participation can mean many things, from differing levels of communication with no input on decision-making (i.e., receiving information or voicing opinions), to directly impacting how a research process unfolds or what the outcomes are (Arnstein, 1969; Green and Hunton-Clarke, 2003; Rowe and Frewer, 2004). Arnstein's "ladder of citizen participation", for instance, describes three general levels of engagement: non-participation, tokenism (i.e., symbolic participation or lip service) and citizen power (Arnstein, 1969).

In principle, it is possible for stakeholders to participate in knowledge production through a variety of functions-from designing a project proposal to contributing to a scientific article, for example (Polk, 2015; Hickey et al., 2018). In all stages of the process then, possibilities for stakeholder involvement range from exclusion, cooperation, responsibility for the relevant function or question at hand, all the way to ownership. While the depth of stakeholder involvement can be represented as three steps on a ladder like Arnstein's, there is significant room for variation between these steps. Arnstein's typology helps pinpoint both the level of responsibility and the location of stakeholder inclusion in the process. Note that stakeholder involvement does not necessarily mean that the stakeholder performs any given task, as they can also hire others (such as scientists) to perform a task on their behalf. This conceptualization can be read in a normative sense-i.e., the more responsibility given to stakeholders, the better, but that is not the argument we make here. We contend that different approaches to stakeholder engagement will result in different levels of stakeholder participation, and that critical reflection on the purpose of participation in any given project is useful. In other words, for some issues, more superficial cooperation may be adequate, but other matters require deeper involvement, like co-production, where stakeholders are, to some degree, also made responsible for the process.

Take the issue of plastic litter, which is addressed by the EU Marine Framework Directive. Stakeholders like fishers might have relevant information depending on the project's aspects of interest. If visual plastic in fish stomachs is used as an indicator of marine litter, for example, this is something that is easily observed by fishers in their daily operations and, thus, their knowledge is relevant. But, if microscopic particles in fish stomachs are to be a primary metric of litter, then fishers will likely not be able to lend their knowledge to the project, as this metric does not allow for observation with the five perception senses, unaided by instruments. Hence, fishers' knowledge is not relevant in and of itself, yet one can argue that since fishers are well-positioned (while catching fish at sea) to provide relevant knowledge, it makes sense to train them in scientific methods that allow for the observation of microscopic particles. Since participation can mean many things to different people, this type of exercise is useful in ensuring legitimacy and avoiding disappointment, which can cause accusations of merely paying lip-service to their involvement.

A related issue concerns what it takes to be considered an expert. It is important to highlight that although practice-experts are stakeholders, not all stakeholders are experts. A stakeholder is someone with an interest in a project, or who stands to be affected by it. A practice-expert is someone who will contribute to the knowledge production process. We contend that co-production projects refrain from using the "expert" label if they cannot ensure that the participant in question will be able to engage with decision-making in the project.

One could ask how many knowledge functions must be met or how deep a level of participation must be in order for a stakeholder to be considered an expert. There are, however, no obvious metrics. The notion of expertise is a relative term and depends on the processes by which cognitive authority is granted (Bjørkan, 2011). Simply put, the concept of cognitive authority indicates that people rely on others to acquire knowledge that is outside their scope of experiences (Wilson, 1983). While reliable and relevant knowledge can be obtained through training or by practicing a skill, the delineation of "expert" is achieved through the social processes of allocating authority to some person or group. While there are exceptions, in most established management regimes (e.g., fisheries management, aquaculture management) the expert role is the exclusive privilege of institutions like the International Council for the Exploration of the Sea and the scientists working for them.

Identifying a project's relevant stakeholders and prominent practice-experts is like aiming at a moving target. What is most important is to reflect upon these questions of stakeholder knowledge and participation intently, honestly, and explicitly.

\section{GUIDANCE FOR EXECUTING RESEARCH PROJECTS BASED ON CO-PRODUCTION OF KNOWLEDGE}

In this section, we expose what we see as typical but underdiscussed challenges that arise as project leaders go about operationalizing principles of co-production. These issues have been distilled from our concrete experiences with this approach, but the following list is not exhaustive or definitive. Possible solutions and further systematic empirical investigation are most welcome. As we use examples and relevant supporting literature to make cases for how to address common challenges, we primarily address the project leader or principal investigator, but all participants can find value in these insights. Figure 1 summarizes our recommendations.

\section{Unite Diverse Participants Through a Shared Objective and Manage Divergent Motivations}

The notion of "co"-production hinges on the assumption that a bond is created across heterogeneous contributors. A project's purpose and objectives are the first components of bringing together participants and building community. However, 


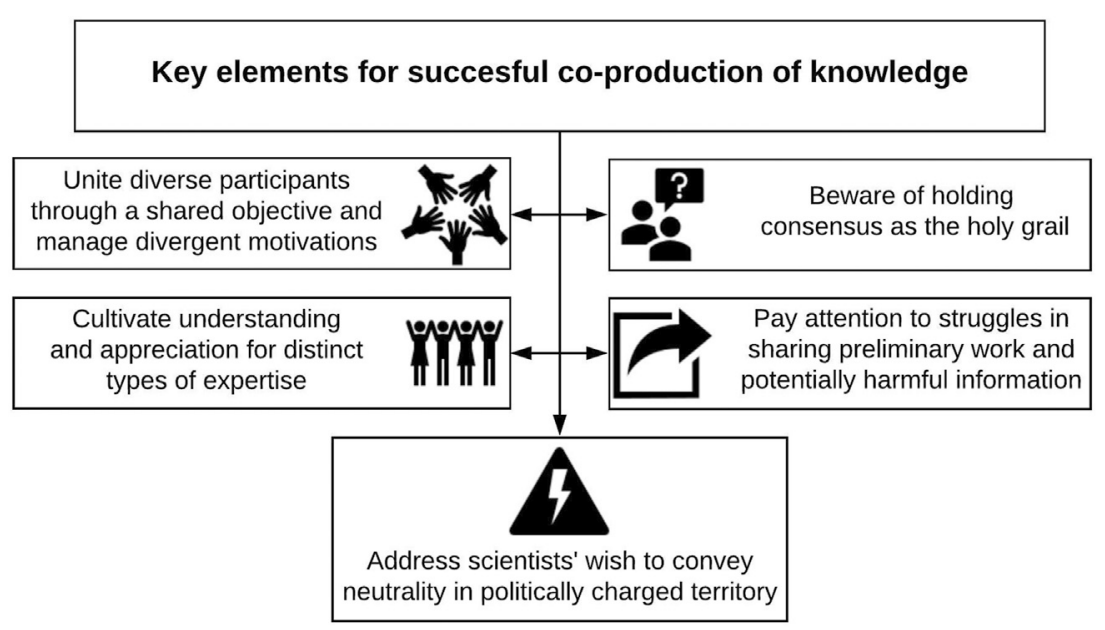

FIGURE 1 | Summary of recommendations.

uniting diverse contributors demands an awareness of what motivates each group, and how distinct motivations can align with a shared objective.

Misalignment between what motivates distinct stakeholders to participate and what they find they get out of the project brings about challenges in communication and execution. While individuals' own motivations may be clear, they often overlook what is at stake for other groups of collaborators. For instance, scientists' motivations to engage in a project may include a desire to understand a phenomenon or the need to publish and advance one's career. For them, a worthwhile output is knowledge in an abstract sense, and publications that are more concrete. In this fashion, scientists behave according to an ethics of conviction (Kim, 2019), i.e., they are committed to truth and to contributing to a "knowledge commons".

Arguably, the motivations of practice-experts are more sensitive to immediate problems at hand. That is, they often want to promote or inhibit a specific behavior or policy, and a worthwhile result for them is change. Practice-experts are guided by an ethics of responsibility, i.e., they are committed to consequences (Kim, 2019). This is not to say that scientists do not care about action or that practice-experts are oblivious to advancing knowledge. Rather, actors themselves are embedded in structures that seek to guide how they behave and what they prioritize, and thus what primarily drives scientists is often different from what motivates practice-experts. Especially relevant among these structural factors are performance metrics, which traditionally have not valued or rewarded coproduction-although, with recent years' focus on signaling impact, this is changing (Durose et al., 2018; Lemos et al., 2018). Highly structured and quantitative performance metrics are saliently institutionalized in academia, but by no means absent in other professional contexts that can be of relevance in a project.

While some of these drivers are known beforehand, at least in principle, it is fundamentally important to go beyond these archetypes and assess drivers and expectations for specific contexts and project stakeholders. Creating a statement of purpose and goals is, therefore, no trivial matter. A project's objective needs to be as concrete as needed in order to be meaningful, and as comprehensive as possible for all participants to recognize it as aligned with their own goals.

One strength of science is that it affords access to knowledge that would otherwise be unreachable through experience alone. In science, one may choose from numerous technologies to help understand nature as a quantifiable, comparable, and subsequently controllable and manageable object for advisory bodies (Asdal, 2003). This should also be discussed in coproduction of knowledge processes to ensure a realistic starting point.

Early negotiations of project objectives happen at the stage of project design, most often before the project has any funding. Still, it is an important stage, specifically because the project can be hampered when the broader set of stakeholders is not engaged with design and only comes onboard after the project descriptions and objectives are set. When this happens, stakeholders' interests and knowledge are bound to be subject to a pre-existing agenda, which influences the way science-experts and practice-experts interact. When this is the case, it becomes even more crucial to take the time to consider how each participant understands the stated goals, how distinct motivations can be aligned, or how unsolvable misalignments can be addressed. At the same time, it is vital to keep in mind that motivations and outcomes are distinct, as we discuss next.

\section{Beware of Holding Consensus as the Holy Grail}

While alignment of objectives is important, consensus of decisions is a different matter. Consensus is an elusive target. Insisting on not acknowledging dissensus, however, can lead to shallow or disappointing outcomes (Hillier, 2003; Barry and Ellis, 2011), especially in the post-normal context and when the endresult creates winners and losers (Bjørkan and Rybråten, 2019; Bjørkan and Veland, 2019). 
Recognizing the problem of holding consensus as the "holy grail" of a project's success is of particular importance, since coproduction of knowledge processes are often deliberative in nature. As such, arenas for co-creation should be organized in line with the ideals of deliberative democracy, i.e., that collective reasoning between actors is the most legitimate and superior means of making decisions (Meadowcroft, 2004; Lövbrand et al., 2011). The deliberation process should take place in a space free from manipulation and the exercise of power. In general, deliberative democracy has faith in consensus and that "public reason-giving is the best way to uncover what is good and true" (Lövbrand et al., 2011, p. 6).

The deliberative turn has been criticized by many (e.g., Mouffe, 2000; Pløger, 2004). Bäckstrand challenges the assumption that broad participation in decision-making will bring about more legitimate and effective policy outcomes (Bäckstrand, 2010). In the same vein, Johnson et al. underline that even if something is perceived as legitimate, it can be both inefficient and inequitable (Johnson et al., 2006). Yet, legitimacy is difficult to measure, since it is not directly observable, and consensus in deliberative democracy does not deal well with conflict. Consensus-based approaches seek to overcome conflict, but in practice they mask the fact that conflicted power relations become stabilized only temporarily and are often characterized by thin agreements at the lowest common denominator (Mouffe, 2000; Hillier, 2003; Porter, 2011).

This problem has been shown in action in the context of including stakeholders in the revision of the Norwegian management plan for the Barents and Lofoten seas (Dale, 2016). The initiative sought to include multiple voices and concerns while making a distinction between "knowledge contributions" and "public opinions". However, the decision on what constituted knowledge took place behind closed doors and resulted in a report that included input almost solely from physical/natural scientists, but which was presented as a consensus, as if everyone involved had produced this consensus. What passed for consensus then was, in fact, artificial and shallow, since a substantial portion of stakeholders (who were included in the process in a more symbolic than tangible way) had it imposed upon them. A focus on consensus also narrows the range of issues that gets to the table (Law, 2004; Scott, 2016). Actors who attended an open hearing reported that, after a number of scientists and Ministers from the government had explicitly talked about the need for solid, scientific knowledge as the foundation for decision-making, they found no room for their contributions in the process (Dale, 2016).

Aiming for consensus hides a foundational trait in modern politics: the desire to research oneself out of political and ethical decisions that are either controversial, contrary to ideological standpoints or challenging to electoral campaign promises. This is the flipside of knowledge-based decision-making. The construction of an imagined, definite barrier between science and politics (from both sides of the fence) shifts the responsibility of decision-making from politicians to scientists, who are portrayed as "objective truth tellers", as if scientific knowledge were stable and immutable. This also puts pressure on scientists, who insist on avoiding political preconditions and implications in their work-a notion that oversimplifies the relationship between science and political power (Bjørkan and Hiis Hauge, 2019; Douglas, 2005; Foucault, 2007; Latour, 1987, 2004).

While simple solutions to complex problems are hard to find, the issue of consensus likely cannot be solved. One way forward, then, is to come to terms with this realization and create a space in which there is high tolerance for respectful conflict. Such an approach involves making explicit the multiple values underlying the conflict, as well as generating an atmosphere of respectful disagreement. This can be challenging, because while one can expect the result to be less conflict, it can also generate suspicion and distrust, and hence more conflict (Johnson et al., 2019). We cannot propose a one-size fits all solution to this complexity. What is important is that scientists in charge of co-production approaches are aware of conflicts and give room for transparent negotiation and compromise based upon open discussions of incommensurate values and choices (Stoffle et al., 2020). We put forth the pragmatic position that the resolution of a conflict will likely not represent enthusiastic consensus (Hillier, 2003), but being involved in a discussion concerning tensions and controversies may actually facilitate the de-escalation of conflicts.

As a result, while decision making processes that explicitly address multiple values do not guarantee that the chosen way forward will account for all parties, they can tame the level of conflict to a manageable degree. This requires tolerance and the creation of spaces for the expression of conflict without abuse; it requires participants to be willing to look beyond their rights and righteousness, empathize with their adversaries, and be curious about uncovering what underlies the other side's position (Hillier, 2003). This, however, relies on an understanding-if not an appreciation-for others' values, knowledge, interests, and motivations in an empathetic manner.

\section{Cultivate Understanding and Appreciation for Distinct Types of Expertise}

Diversity of backgrounds and types of expertise is not a barrier to creating a cohesive project team, but overlooking differences can create problems. In addition to the question of what is at stake for each actor, it is imperative to create a shared understanding of why each participant has relevant knowledge that warrants their engagement in the project (i.e., their epistemological background and legitimacy), and what world views (ontologies) and values (axiologies) inform their attitudes and contributions to the project. Clarifying these aspects is important because practiceexperts and experts from distinct scientific disciplines occupy different positions of status and power in society, and a genuinely co-produced approach requires that the worth of all participants stand on equal footing with mutual authority.

This appears to be a challenge for scientists, since many are inexperienced in evaluating and valuing knowledge from sources other than science. This is not only the case when scientists decide the direction of a project and where to look for data, but also in deciding why they should research, what they should look at, and how to conclude their research and subsequently advise. Yet, practice-experts can be valuable in a variety of research strategies. 
In research projects that rely on deduction, practice-experts can take part not only in data collection, but also in the interpretation of findings and their implications. This is also the case, perhaps even more so, for projects that rely upon induction. That is, rather than starting with a hypothesis, such projects begin with a grounded observation of what is going on in the world, and very often a preliminary hunch of the causes for the event in question. Practice-experts can be invaluable in these early observations. Finally, projects that rely on abduction (i.e., from observations to inferences to the best explanation, Danermark et al., 2001) can benefit from practice-experts for the interpretation of phenomena and to construct rich, contextualized explanations.

It is the role of the project leader to consider how to promote these interactions and not succumb to downplaying knowledge from practice-experts or inputs from stakeholders, including when these inputs question the very rationale of the research. Accordingly, the project leader must also ensure that practiceexpert and stakeholder information is communicated throughout the project. Information flow is fundamental for effectively including non-scientists in both the research process and the formation of a research agenda. In practice, this means that each participant (or group of stakeholders in large partnerships) needs to be aware of how other participants contribute to the overall project objective, and why that contribution is valuable. Inclusion also requires new conceptualizations of what knowledge is, which knowledge is relevant, which knowledge is not relevant and why (i.e., boundary work, Gieryn, 1999). As such, co-production as a method challenges the usual set of activities that scientists carry out with little consideration, precisely because they have become standard.

Therefore, co-production research can be demanding to the project leader, who is tasked with keeping collaborations running smoothly. The ability to manage people is a necessary skill in this context. The scope and resources of each project determines how thoroughly this analysis of stakeholders can and ought to be carried out. At a minimum, it is useful for the project leader to reflect on these questions of knowledge, introduce their concerns during the design phase of the project, and continue to voice their opinions as the project begins.

A widespread appreciation of others' knowledge and expertise is also helpful in dissociating people's identity from the knowledge they bring to a project. This is critical to securing a participant's legitimate position in a project, as well as confidence in their contribution even if their preconceived notions are shown to be mistaken-for instance, if an initial observation or hypothesis turns out to find no support in the data. Scientists know all too well how the peer-review process can be both unpleasant and necessary. Arguably, at the core of science is the inclination to judge all knowledge claims with organized skepticism. This is especially crucial if the issue at hand affects society at large: knowledge claims about issues such as food, health, ecosystems and so on cannot be considered truly independent from whomever makes the claims. The claims must go through some quality control-a tenet upheld by the co-production approach and extended peer-review processes. Hence, any knowledge claims must be scrutinized and questioned.
Practice-experts are more vulnerable to having their expertise questioned, but the opposite could also conceivably happen. That is, scientists run the risk of putting forth interpretations or hypotheses that do not hold up in a specific context, and thus lead to resistance from local communities when engaging with scientific projects, threatening the legitimacy and applicability of potential results. This matters in a world threatened by fake news and anti-science conspiracies. In any case, the purpose of coproduction of knowledge is to increase the salience and robustness of the knowledge that is produced through the meaningful integration of diverse types of expertise. In a research project, no knowledge should be immune from scrutiny, and all assumptions must be open to respectful examination in a way that does not invalidate the identities of stakeholders.

We see the growing focus on inclusion and co-production as a reaction to the traditional power imbalances between science and other knowledge systems-including indigenous practices and experiences. Amidst this pushback, we contend that one can simultaneously: 1) hold the standpoints that no knowledge systems ought to be given epistemological privileges, 2) be aware that power differences do exist, 3) acknowledge that different forms of knowledge have different virtues and shortcomings, and 4) uphold the importance of science. Our recommendation is to address questions of knowledge and power explicitly and to ensure that inclusive methods are implemented in knowledge production processes that leave room for other types of knowledge, where science is not able to contribute (Bremer and Meisch, 2017). In the same vein, discussions on civic science have facilitated the inclusion of multiple knowledge traditions de facto in the science-policy interface, and thus ensures an understanding of the need for knowledge to be inclusive in order to maintain legitimacy (Bäckstrand, 2003).

Despite the effort required upfront, these precautions promote a fruitful work environment, improve the quality of exchanges, and also open the door for stakeholders to express their dissent when it arises. As previously discussed, by taking the time to engender understanding and appreciation for distinct types of expertise, heterogeneous project groups become better positioned to engage in debate when dissensus arises (Mouffe, 2000; Hillier, 2003). Failure to explicitly address these issues in the project can lead to miscommunication, misunderstandings, lack of rapport and the creation of dysfunctional hierarchies amongst project participants. This, in turn, leads to thin agreements that risk being little more than a front for incumbent interests and powers paying lip-service to stakeholder engagement. Genuine knowledge co-production depends on a shared appreciation for one another's backgrounds, roles, and contributions.

\section{Pay Attention to Struggles in Sharing Preliminary Work and Potentially Harmful Information}

In a (Kuhnian) normal scientific paradigm, knowledge production appears to take place in a linear fashion, beginning with the identification of research questions, and ending with the publication and dissemination of results. In a post-normal paradigm, this appearance of linearity is disrupted, processes 
that normally lie in the background are exposed to a broader audience, and information must be exchanged even if it has not been processed to its finished state. Whether this information concerns untested hypotheses, undecided premises or preliminary data, the reality of co-production projects is that scientists are pushed to be open about work with which they might be uncomfortable or unsure of.

This conflict is related to the cognitive authority of science in the public arena, which demands effort to generate and maintain (Wilson, 1983). Science and Technology Studies refer to frontstage performances (Hilgartner, 2000), purification (Latour, 1987) and boundary work (Gieryn, 1983; Gieryn, 1999) as processes that play a role in establishing cognitive authority. Most notably, Latour differentiates between "science-in-the-making" (when knowledge claims are still subject to revision and disagreements are seen as an integral part of the process) and "ready-made science" (the final, cleanedup product put forth as scientific fact) (Latour, 1987). Coproduction processes invite new actors to the backstage of science-in-the-making, and this can be new and uncomfortable to many scientists.

While scrutiny of preliminary work is common in academia_such as a conference presentation or peerreview-it usually happens between specialists that have the same background competence. The presence of practiceexperts creates an uneven baseline for knowledge sharing. This gives rise to a fear that information could be misinterpreted or misused. Reluctance to share preliminary work is also associated with scientists' loss of control concerning the narratives that are derived from their work. When scientists disseminate work done in the intellectual safety of their labs, they have better command of what interpretations will come from their results and how those results will be communicated. Forfeiting control over these aspects also threatens a scientist's ability to convey impartiality.

The recommendations we have offered thus far (i.e., establishing shared goals, creating space for respectful debate and conflict, and promoting adequate understanding of partners' motivations and expertise) aim to create trust that mitigates the struggle of sharing preliminary work. Nonetheless, it is important that project leaders pay attention to this type of conflict so as to avoid hindering information exchange. Acknowledging these challenges beforehand also brings to mind the fact that scientists' degree of confidence in the information they share can be substantially diminished. It can then be useful to point to the positive aspects of sacrificing the intellectual comfort-zone. That is, in the true spirit of coproduction, data, procedures, and assumptions will be scrutinized and debated early on, with the expectation that this will lead to better quality knowledge with high validity, contextual relevance and impact.

A similar problem can afflict practice-experts, who might be hesitant to share information if they perceive that doing so will affect them negatively. For instance, in the case of the Norwegian Reference Fleet, we see many instances in which fishers share information about illegal, unreported and unregulated fishing practices. This can affect them at a personal level, by incriminating them or affecting the size of the total allowable catch and, by extension, their income. In this particular arena, several measures have been put in place to ensure a trust-based information flow (Bjørkan, 2011).

Project leaders might also detect a kind of observer effect, in which participants modify their behavior or stage their performances in a group setting when they know they are being observed or evaluated (Monahan and Fisher, 2010). Experienced project leaders are aware of such performativity. They can then check for validity and triangulate information accordingly, and even potentially harness this display of rehearsed behavior to the benefit of the research project (Monahan and Fisher, 2010).

Pushing project participants, whether they are scientists or practice-experts, to share their work and knowledge without the necessary precautions and preparations can lead to problems that will ultimately damage the project. Participants may become selective and strategic in relation to what they put forth and what they hold back. By cherry-picking the most desirable or least controversial bits of information, the project misses worthwhile discussions and, in the worst cases, lacks integrity in research and damages validity of results.

Though well-intentioned, reminding project participants of the importance of sharing freely is insufficient. Project leaders need to build sufficient trust among stakeholders. Otherwise, if stakeholders perceive sharing to be a personal threat, it is reasonable to expect that they will omit or directly withhold information that could lead to a different research picture. Cherry-picking refers not just to pieces of data and results, but to all aspects that can be manipulated in a research process, including the research design, which may have implications for a specific industry or political actor, as the quote below illustrates.

"It is easy for us researchers to cherry-pick and influence results if one wants to. Luckily, this is not what motivates us".-Quote by a scientist in a co-production workshop.

In the above quote, the scientist was reflecting upon the process of establishing the assumptions that would inform a model designed in partnership with scientists and practiceexperts. Depending on which premises were established, results could be used to assign or dismiss blame in a given industry for an environmental problem. The team was aware of their responsibility and of the political implications of engaging with a post-normal research problem. At the same time, they wanted to assert neutrality not only in relation to the results, but also in the very assumptions and premises adopted for the research, itself. This leads us to our final recommendation.

\section{Address Scientists' Wish to Convey Neutrality in Politically Charged Territory}

Whereas the previous point concerned participants' positions within the project, we turn now to their relationship with actors outside the project group. As we touched upon in the previous section, most scientists (though not all, in our experience) are used to caring for housekeeping behind the scenes (e.g., cleaning up datasets, fine-tuning methodological approaches, discarding negative results before publishing, trial-and-error testing of hypothesis) and only reach out to the public once there is 
consensus and they can speak with a stronger, unified voice. Scientists assert their authority precisely by means of their commitment to truth over convenience; taking any position in a disputed problem threatens this projection of neutrality (Skolnikoff, 2001). This tension is especially salient in times of fake news and public discrediting of scientific expertise, and scientists may fear taking a public position that can turn out to be disproven later (e.g., Oreskes and Conway, 2010). Thus, scientists may worry about damaging their reputation, credibility, and authority, which is already under threat in some circles.

However, science and scientists are becoming increasingly challenged in the public eye (Skolnikoff, 2001). Among several reasons for this, we highlight the prominence of evidence-based policy and management in which politicians push science to the fore of their decision-making, forcing science "on stage" to make statements about issues where research is preliminary or controversial (Saltelli and Giampietro, 2017). The general public, in turn, lacks an understanding of how science deals with uncertainty, which hinders honest and effective debate (Bjørkan and Hiis Hauge, 2019).

The Norwegian aquaculture sector is a good example of how scientists have been under pressure from both politicians and business representatives (Bjørkan and Hiis Hauge, 2019). They fear that uncertainty will be mishandled or misconstrued to push an agenda amidst a conflict of interest. Two quotes exemplify this concern:

"When we talk about who is going to confront the sources (of pollution), I think it is important that it is not us researchers who are going to do it because we produce the knowledge that someone else is going to use. As a researcher, I should not be the one to say, "This cannot be allowed". Here, it is someone else who should make the decision in a democratic way. In the long term, this could eventually damage my reputation as a scientist who needs to tell the truth but not have too many opinions at the same time".

-Quote by a scientist in a co-production workshop.

"For an NGO, it would be catastrophic to form an alliance with scientists who have an agenda. It would undermine what we do".

-Quote by the director of an NGO in a co-production workshop.

That is, not only do scientists prefer to adopt a posture of neutrality, but other stakeholders also expect this of them (Skolnikoff, 2001), even though there is an argument to be made for taking sides (i.e., Rosendahl et al., 2015). Scientists are presumed to make assertions backed by multiple qualifications, limiting conditions and caveats, while practice-experts (and the press) are more eager to dismiss these qualifications and work only with the substance of findings and arguments. If practice-experts need support from project leaders to assert their legitimacy towards the group, scientists need support to explore and document the limiting conditions of the knowledge they put forth. This support contributes to trust and prevents scientists from experiencing " $a$ dilution of the authority of science" and being "dragged into the world of politics" (Ravetz, 1999). As a result, scientists will be more at ease to express ideas that may be preliminary, uncertain, or politically charged. Allowing scientists space to be cautious precludes them from evading or concealing the policy implications associated with their work.

\section{SOCIAL SCIENTISTS' CONTRIBUTIONS TO CO-PRODUCTION OF KNOWLEDGE}

Based on our experience-which the advice we put forth in this paper reflects-much of what can be challenging in coproduction research is of a tacit and social nature. Stimulating exchanges between scientists and practice-experts is only the first step in successful co-production of knowledge. What comes next relies upon the kind of soft skills that can be (and often are) taken for granted. These kinds of contributions, which are more difficult to articulate and measure, are often at the very core of what social science and humanities experts can offer (Turner, 2015). Thus, the contributions from "hard-discipline" scientists and practice-experts are generally more applied than those of social scientists.

Different actors have different expectations for social scientists. Some practice-experts, such as indigenous or marginalized groups, are in a more vulnerable position in the configurations of power and might expect social scientists to assist them in making their voices heard and to voice concerns regarding social justice issues. Other practice-experts (e.g., NGOs with international reach) have no problem voicing their knowledge and perspectives. Often, employees in NGOs have academic degrees and enter partnerships with scientists active in academia. Moreover, with the decline in permanent positions in scientific careers, many doctoral graduates look for jobs outside academia after earning their degrees. Natural scientists often expect social scientists to build communication channels between themselves and practice-experts, and to ensure that people "get it". But natural scientists are also less open to critical social inquiry into, for instance, how scientific knowledge is produced as an expression of a particular knowledge culture (Latour, 1987) and less focused on their roles as gatekeepers of and contributors to large, powerful, and segregated communities of experts (Jasanoff and Kim, 2015).

One of the most common expectations put upon social scientists is that they should serve as brokers between other scientists and practice-experts, facilitating the implementation of research projects, enabling contact between stakeholders from diverse backgrounds, and solving logistical problems. While these are indeed tasks that social scientists can and often do take on in co-production projects, it would be unfortunate to limit the scope and ambitions of social scientists to mere facilitation. This is both an inefficient use of project resources (since other professionals can perform these tasks) and a devaluation of the contributions social scientists can offer. We therefore stress in our recommendations here that social scientists be allowed the space and resources needed for thorough and analytical social science research and reflection. Naturally, these contributions should aim at a better understanding not only of the practical 


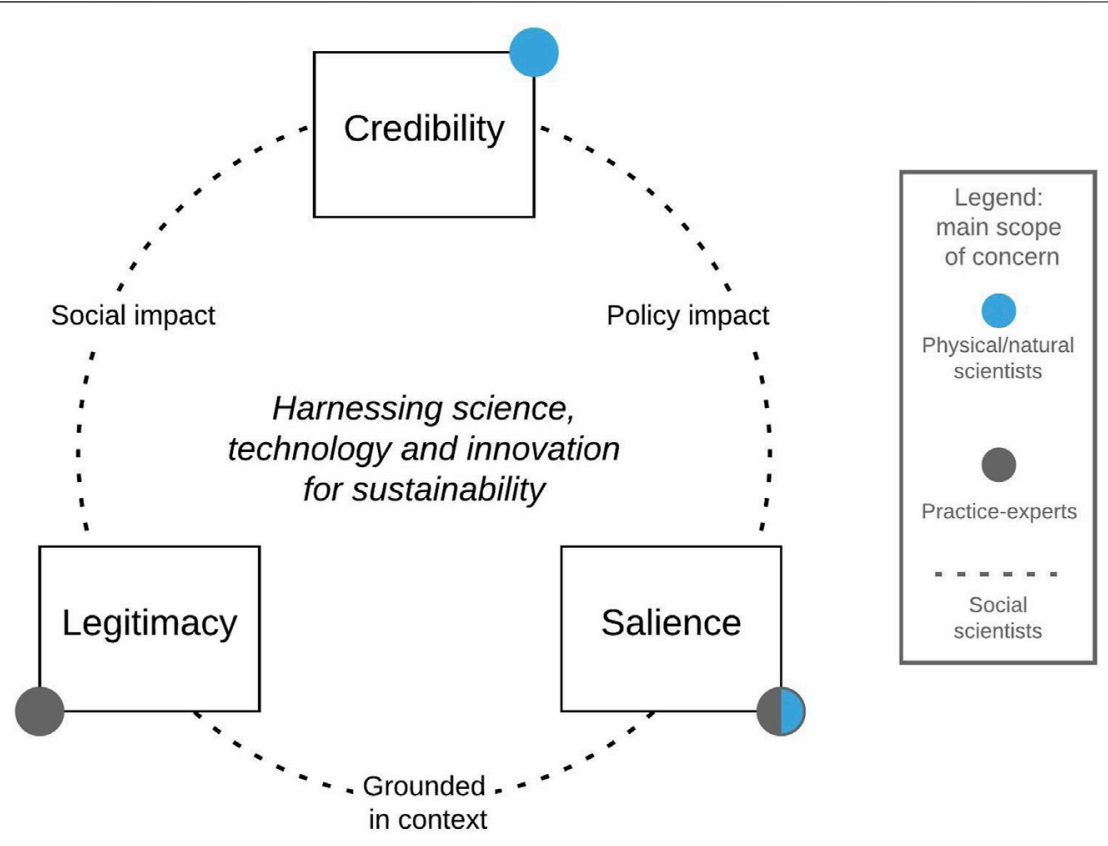

FIGURE 2 | Credibility, legitimacy and salience (inspired by Cash et al., 2003).

obstacles to solving a particular societal problem, but also of how project goals align with and/or contradict the rights, concerns, goals and ambitions of multiple actors and stakeholders.

We further assert that this narrow view of the social scientist's role more often reflects a lack of familiarity with what the social sciences do than a lack of valorization of the field as a systematic field of inquiry. That said, many expect social scientists to "handle" the social, the political and even the economic implications of a project, as if these were nuisances and hindrances instead of integral elements of knowledge production in a post-normal context. This tendency towards accepting the incomplete picture is unfortunately not often challenged by funding agencies, which assign social science contributors the role of ensuring society's readiness to accept a project's innovations and subsequent implementation of results through favorable policies. In our anecdotal experience, projects (and calls for projects) that center around hard technology development and technical solutionfinding in pathways that are politically pre-decided are most often guilty of misusing co-production and the social sciences.

It is important that social scientists are more than the "icing on the cake" in transdisciplinary funding applications (a characterization that one of us has heard from a natural scientist). Social scientists can and should contribute as more than project advocates performing for social actors who influence and are influenced by the project and its results. However, if we are to acknowledge the ways in which social scientists can meaningfully contribute to transdisciplinary coproduction in research projects, it is imperative to accept that the contribution of social scientists is often intangible. What is more, we should see and frame this intangibility as an asset. While some actors provide hard data measuring a phenomenon, create an innovative prototype, or produce a number of other material deliverables, social scientists' contributions are distinctive in that they can illuminate multiple potential outcomes, multiple assessments and understandings of the problem at hand, and the awareness that, no matter what contributions a project provides in the end, society will proceed not without arguments, disagreements, insecurities and contingencies, but through them (Foucault, 2008; Dean, 2010; Dale, 2011).

Earlier work on how to harness science, technology and innovation for sustainability transitions has shown that successful cases are those in which there is a balance between credibility, salience, and legitimacy of knowledge (Cash et al., 2003). The challenging task is to enhance these three dimensions simultaneously, as efforts in one area often impact the others (Cash et al., 2003). We consider social scientists' contributions to lie in promoting and maintaining ties between credibility, legitimacy, and salience, as illustrated by Figure 2 .

Just as the social sciences are diverse, there are multiple ways in which different disciplines can contribute to a research project. What is shared across disciplines-from anthropology to economics-is that social scientists can ask unusual questions, visualize the bigger picture, analyze the complexities in which an issue is embedded, and form connections between a project and other relevant problems for mutual learning. Social scientists can map and document how different processes unfold and create analytical toolboxes for the social, political, and economic aspects relevant to a project. It is the job of social scientists to create space for critical reflection on a project's process and results, and to address the ways in which the process both influences and is influenced by society at large.

Social scientists can also play a role in consistently operationalizing methods that prevent the misuse of a research process by any given group, and thereby calibrate the scales of 
power in knowledge production (Turnpenny et al., 2011). Emphasizing and utilizing this ability would be beneficial not only to social scientists, but to all stakeholders and, not least, to the production of knowledge that measures up to the ideals of credibility, salience, and legitimacy.

\section{CONCLUSION}

In this paper, we sought to offer practical guidance to researchers interested in adopting co-production of knowledge in their work. Increasing demands for the adoption of co-production in scientific research is noticeable, whether through the EU's multi-actor approach, stakeholder engagement, citizen participation and other related notions. While there are nuances to these labels, what they have in common is the social justice premise that diverse stakeholders have not only the moral right to participate in knowledge production and decision making that affects them, but also that actors other than scientists have expertise that matters and should be better accounted for. More democratic processes of both production and consumption of knowledge also reframe knowledge and expertise as a commons, rather than privileged, exclusionary, and rival arenas.

While there is a rich literature in Science and Technology Studies that deals with science as process and culture, knowledge (co-) production, public engagement, and power, among other aspects, we observe that these insights are often unfamiliar to scientists leading research projects. Often, project leaders either learn through trial and error and lack deep understanding of these issues, or they remain oblivious to the socio-cultural dynamics that affect knowledge production. To address this pressing need, we have revisited key works and arguments from the STS tradition in light of our experiences and what we see are concrete challenges involved in co-production of knowledge. Our ambition has been to build upon this knowledge, extend it to a broader audience, and illustrate its intricacies with practical guidance.

Our main contribution is in putting forth five crucial elements that arise as project leaders go about operationalizing principles of co-production. Our core recommendations are: 1) unite diverse participants through a shared objective and manage divergent motivations; 2) beware of holding consensus as the holy grail; 3) cultivate understanding and appreciation for distinct types of expertise; 4) pay attention to struggles in sharing preliminary work and potentially harmful information; and 5) address scientists' wish to convey neutrality in politically charged territory. Binding these recommendations is the need for project leaders to develop soft skills for coordinating collaborative work in a way that foments trust and goodwill, despite possible conflicting values and interests.

We also call attention to the role of social scientists in transdisciplinary collaborations of this sort, which we see as crucial for promoting and maintaining ties between credibility, legitimacy, and salience of the research process. The contribution of social scientists is often less tangible than other types of experts, but their inherent value needs more recognition, both in the form of wider acknowledgement and as allocation of funds for these tasks in research projects. We believe this is fundamental to avoid that coproduction becomes a bureaucratic box-checking, or worse, that it gets coopted as devices for granting the appearance of participation to processes that are in fact not in essence concerned with it.

This article was not conceived to be exhaustive or definitive, but to advance a dialogue on the challenges that come about when operationalizing co-production in practice. We hope to motivate others to share their experiences, and, in doing so, contribute to a toolbox equipped to realize collaboration and knowledge production across diverse values, disciplines and expertise.

\section{AUTHOR CONTRIBUTIONS}

$\mathrm{LN}$ was co-responsible for the conception of this manuscript, and the primary responsible for its framing, development, writing and editing. MB was co-responsible for the conception of this manuscript and contributed to the framing and co-writing of all sections of the manuscript. BD contributed to the framing of the article, contributed particularly to the Introduction, the section on consensus and the section on Social Scientists' Contribution to CoProduction Processes, and commented upon all other sections.

\section{FUNDING}

The experiences that form our insights and analyses in this article stem from multiple research projects, whose respective publications are mentioned at the end of the introduction. For the formulation and writing of this paper, the authors received funding from the Fram Centre Flagship Plastic in the Arctic 2019-2021 (Grant No. 469), through the BARRICADE project, led by the Norwegian Meteorological Institute. The authors were responsible for designing the co-production element of the project and implementing the work package concerning stakeholder-researcher dialogue. The funding sources were not involved in the preparation or decision to submit this article.

\section{ACKNOWLEDGMENTS}

The authors are indebted to all participants and stakeholders involved in the research projects upon which we base our reflections. We thank especially Johannes Röhrs, Kjersti Opstad Strand, Cecilie Mauritzen, and Tadeu Fernando Nogueira for their feedback on an earlier version of the manuscript, and Tord Apalvik, Casper Gamborg Holm and Louise Brøns Kringelum for their logistical help. All mistakes are ours alone. 


\section{REFERENCES}

Alvial-Palavicino, C. (2016). The Future as Practice. A Framework to Understand Anticipation in Science and Technology. Tecnoscienza: Ital. J. Sci. Techn. Stud. 6 (2), 135-172.

Aminpour, P., Gray, S. A., Jetter, A. J., Introne, J. E., Singer, A., and Arlinghaus, R. (2020). Wisdom of Stakeholder Crowds in Complex Social-Ecological Systems. Nat. Sustain. 3 (3), 191-199. doi:10.1038/s41893-019-0467-z

Arnstein, S. R. (1969). A Ladder of Citizen Participation. J. Am. Inst. Planners 35 (4), 216-224. doi:10.1080/01944366908977225

Asdal, K. (2003). The Problematic Nature of Nature: The Post-Constructivist Challenge to Environmental History. Hist. Theor. 42 (4), 60-74. doi:10.1046/ j.1468-2303.2003.00257.x

Bäckstrand, K. (2003). Civic Science for Sustainability: Reframing the Role of Experts, Policy-Makers and Citizens in Environmental Governance. Glob. Environ. Polit. 3 (4), 24-41. doi:10.1162/152638003322757916

Barry, J., and Ellis, G. (2011). "Beyond Consensus? Agonism, Republicanism and a Low Carbon Future," in Renewable Energy and the Public: From NIMBY to Participation. Editor P. Devine-Wright (London, United Kingdom: Routledge), 29-42.

Bergmann, M., Mützel, S., Primpke, S., Tekman, M. B., Trachsel, J., and Gerdts, G. (2019). Sophia Mützel, Sebastian Primpke, Mine B. Tekman, Jürg Trachsel, and Gunnar Gerdts. White and Wonderful? Microplastics Prevail in Snow from the Alps to the Arctic. Sci. Adv. 5 (8), eaax1157. doi:10.1126/sciadv.aax1157

Bjørkan, M. (2011). Fishing for Advice: The Case of the Norwegian Reference FleetTromsø. Tromsø, Norway: University of Tromsø.

Bjørkan, M., and Hiis Hauge, K. (2019). Kunnskapsbasert Forvaltning Og Dilemmaer Knyttet Til Usikkerhet. Oslo, Norway: Cappelen Damm Akademisk/NOASP, 107-130. doi:10.23865/noasp.63.ch5

Bjørkan, M., and Rybråten, S. (2019). The Potential Impact of Sea Lice Agents on Coastal Shrimp in Norway: Risk Perception Among Different Stakeholders. Maritime Stud. 18 (2), 173-187. doi:10.1007/s40152-019-00141-6

Bjørkan, M., and Veland, S. (2019). Beyond Consensus: Perceptions of Risk from Petroleum Developments in Lofoten, Vesterålen, and Senja, Norway. ICES J. Mar. Sci. 76 (6), 1393-1403. doi:10.1093/icesjms/fsz056

Bonanno, G., and Orlando-Bonaca, M. (2018). Ten Inconvenient Questions about Plastics in the Sea. Environ. Sci. Pol. 85 (July), 146-154. doi:10.1016/ j.envsci.2018.04.005

Boswell, C., and Smith, K. (2017). Rethinking Policy 'impact': Four Models of ResearchPolicy Relations. Palgrave Commun. 3 (1), 1-10. doi:10.1057/s41599-017-0042-z

Bremer, S., and Meisch, S. (2017). Co-production in Climate Change Research: Reviewing Different Perspectives. Wires Clim. Change 8 (6). doi:10.1002/wcc.482

Brey, P. (2018). The Strategic Role of Technology in a Good Society. Techn. Soc. 52 (February), 39-45. doi:10.1016/j.techsoc.2017.02.002

Busch, K. E. T. (2015). Reker Dør Av Lakselusmedisin. Available at: https://forskning. no/hav-og-fiske-fiskesykdommer-partner/reker-dor-av-lakselusmedisin/483602 (Accessed July 13, 2015). doi:10.1007/978-3-658-09675-5

Cash, D. W., Clark, W. C., Alcock, F., Dickson, N. M., Eckley, N., Guston, D. H., et al. (2003). Knowledge Systems for Sustainable Development. Pnas 100 (14), 8086-8091. doi:10.1073/pnas.1231332100

Chopyak, J., and Levesque, P. (2002). Public Participation in Science and Technology Decision Making: Trends for the Future. Techn. Soc. 24 (1), 155-166. doi:10.1016/S0160-791X(01)00051-3

Coad, A., Nightingale, P., Stilgoe, J., and Vezzani, A. (2020). Editorial: The Dark Side of Innovation. Industry and Innovation 28, 102-112. doi:10.1080/ 13662716.2020.1818555

Dale, B. (2016). Governing Resources, Governing Mentalities. Petroleum and the Norwegian Integrated Ecosystem-Based Management Plan for the Barents and Lofoten Seas in 2011. Extractive Industries Soc. 3 (1), 9-16. doi:10.1016/ j.exis.2015.10.002

Dale, Brigt. (2011). "Securing a Contingent Future: How Threats, Risks and Identity Matter in the Debate over Petroleum Development in Lofoten, Norway. PhD Thesis. Tromsø, Norway: Department of Sociology, Political Science and Community Planning, University of Tromsø.

Dale, B., Veland, S., and Hansen, A. M. (2019). Petroleum as a challenge to Arctic Societies: Ontological Security and the Oil-Driven 'push to the north'. Extractive Industries Soc. 6, 367-377. doi:10.1016/j.exis.2018.10.002
Danermark, B., Ekström, M., Jakobsen, L., and Karlsson, J. C. (2001). Explaining Society: Critical Realism in the Social Sciences. London and New York: Routledge Taylor and Francis Group.

Dankel, D. J., Vaage, N. S., and van der Sluijs, J. P. (2017). Post-Normal Science in Practice. Futures 91 (August), 1-4. doi:10.1016/j.futures.2017.05.009

Dean, M. (2010). Governmentality: Power and Rule in Modern Society. 2nd ed. London; Thousand Oaks, Calif: SAGE.

Derraik, J. G. B. (2002). The Pollution of the Marine Environment by Plastic Debris: A Review. Mar. Pollut. Bull. 44 (9), 842-852. doi:10.1016/S0025326X(02)00220-5

Douglas, M. (2005). Risk and Blame: Essays in Cultural Theory. Digital Paperback London: Routledge.

Dryzek, J. S., and Braithwaite, V. (2000). On the Prospects for Democratic Deliberation: Values Analysis Applied to AustralianPolitics. Polit. Psychol. 21 (2), 241-266. doi:10.1111/0162-895X.00186

Durose, C., Richardson, L., and Perry, B. (2018). Craft Metrics to Value Coproduction. Nature 562 (7725), 32-33. doi:10.1038/d41586-018-06860-w

European Commission (2021). Horizon Europe: The EU Research \& Innovation Programme 2021 -2027. Available at: https://ec.europa.eu/info/sites/default/ files/research_and_innovation/funding/presentations/ec_rtd_he-investing-toshape-our-future.pdf (Accessed March 19, 2021).Horizon Europe: The EU Research \& Innovation Programme 2021 -2027

European Commission (2014). Public Engagement in Responsible Research and Innovation.” Horizon 2020 - European Commission. Available at: https://ec. europa.eu/programmes/horizon2020/en/h2020-section/public-engagementresponsible-research-and-innovation (Accessed March 21, 2014).

European Commission (2013). Societal Challenges." Horizon 2020 - Societal Challenges. Available at: https:/ec.europa.eu/programmes/horizon2020/en/ h2020-section/societal-challenges (Accessed October 22, 2013).

Farrell, K. N. (2011). Snow White and the Wicked Problems of the West: A Look at the Lines between Empirical Description and Normative Prescription. Sci. Technol. Hum. Values 36 (3), 334-361. doi:10.1177/ 0162243910385796

Foucault, M. (2007). Security, Territory, Population: Lectures at the College de France, 1977-1978Lectures at the College de France. New York, NY: Picador.

Foucault, M. (2008). The Birth of Biopolitics: Lectures at the Collège de France,19781979. London: Palgrave Macmillan UK.

Funtowicz, S. O., and Ravetz, J. R. (1993). Science for the Post-Normal Age. Futures 25 (7), 739-755. doi:10.1016/0016-3287(93)90022-L

Funtowicz, S. O., and Ravetz, J. R. (1990). "Uncertainty and Quality in Science for Policy," in Theory and Decision Library: Philosophy and Methodology of the Social Sciences (Springer), 15. doi:10.1007/978-94-009-0621-1

Gieryn, T. F. (1983). Boundary-Work and the Demarcation of Science from Nonscience: Strains and Interests in Professional Ideologies of Scientists. Am. Sociological Rev. 48 (6), 781-795. doi:10.2307/2095325

Gieryn, T. F. (1999). Cultural Boundaries of Science: Credibility on the Line. Chicago: University of Chicago Press.

Granjou, C., Walker, J., and Salazar, J. F. (2017). The Politics of Anticipation: On Knowing and Governing Environmental Futures. Futures 92 (September), 5-11. doi:10.1016/j.futures.2017.05.007

Green, A. O., and Hunton-Clarke, L. (2003). A Typology of Stakeholder Participation for Company Environmental Decision-Making. Bus. Strat. Env. 12 (5), 292-299. doi:10.1002/bse.371

Harrison, P. A., Dunford, R., Kelemen, E., Barton, D. N., Kelemen, E., MartínLópez, B., et al. (2018). Selecting Methods for Ecosystem Service Assessment: A Decision Tree Approach. Ecosystem Serv. 29 (February), 481-498. doi:10.1016/ j.ecoser.2017.09.016

Haward, M. (2018). Plastic Pollution of the World's Seas and Oceans as a Contemporary challenge in Ocean Governance. Nat. Commun. 9 (1), 667. doi:10.1038/s41467-018-03104-3

Hickey, G., Richards, T., and Sheehy, J. (2018). Co-Production from Proposal to Paper. Nature 562 (7725), 29-31. doi:10.1038/d41586-018-06861-9

Hilgartner, S. (2000). Science on Stage: Expert Advice as Public Drama. Writing Science. Stanford, Calif: Stanford University Press.

Hillier, J. (2003). `Agon'izing over Consensus: Why Habermasian Ideals Cannot Be 'Real'. Plann. Theor. 2 (1), 37-59. doi:10.1177/1473095203002001005

Hippel, E. v. (2006). Democratizing Innovation. 1. Cambridge, Mass: MIT Press paperbackMIT Press. 
Holm, P. (2003). "Crossing the Border: On the Relationship between Science and Fishermen's Knowledge in a Resource Management Context. Maritime Stud. 2 (1), 5-33.

Jasanoff, S., Markle, G., Peterson, J., and Pinch, T. (1995). Handbook of Science and Technology Studies. Revised Edition. Thousand Oaks, California: SAGE Publications, Inc.. doi:10.4135/9781412990127

Jasanoff, S., and Simmet, H. R. (2017). No Funeral bells: Public Reason in a 'posttruth' Age. Soc. Stud. Sci. 47 (5), 751-770. doi:10.1177/0306312717731936

Johnsen, H. R., Falk-Andersson, J., Larsen Haarr, M., Roland, A. O., and Sanli, E. (2019a). HAVPLAST: Delrapport - Tiltak Og Indikatorer. Editors I. Bay-Larsen, L. A. Nogueira, B. V. Vangelsten, and V. Pedersen (Svolvær, Norway: SALT Lofoten and Nordland Research Institute), 1034. doi:10.13140/ RG.2.2.21777.79204“

Johnsen, H. R., Haar, M., Roland, A. O., Johannessen, E. R., Bay-Larsen, I., Vangelsten, B. V., et al. (2019b). Sluttrapport HAVPLAST - Marin plast fra norsk sjømatnoring - kartlegging, kvantifisering og handling.”. Svolvær, Norway. SALT Lofoten and Nordland Research Institute. doi:10.13140/ RG.2.2.19071.56485

Johnson, C., Dowd, T. J., and Ridgeway, C. L. (2006). Legitimacy as a Social Process. Annu. Rev. Sociol. 32 (1), 53-78. doi:10.1146/annurev.soc.32.061604.123101

Johnson, D. S., Lalancette, A., Lam, M. E., Leite, M., and Pálsson, S. K. (2019). “The Value of Values for Understanding Transdisciplinary Approaches to Small-Scale Fisheries,". Editors R. Chuenpagdee and S. Jentoft (Cham: MARE Publication SeriesSpringer International Publishing), 35-54. doi:10.1007/978-3-319-949383_3, 21:35-54

K. Bäckstrand (2010). Environmental Politics and Deliberative Democracy: Examining the Promise of New Modes of Governance (Cheltenham; Northampton, MA: Edward Elgar Pub).

Kim, S. H. (2019). "Max Weber," in The Stanford Encyclopedia of Philosophy. Editors E. N. Zalta (Stanford, United States: Metaphysics Research Lab, Stanford University).

Kønig, N., Børsen, T., and Emmeche, C. (2017). The Ethos of Post-Normal Science. Futures 91 (August), 12-24. doi:10.1016/j.futures.2016.12.004

Kristoffersen, B., and Dale, B. (2014). Post Petroleum Security in Lofoten: How Identity Matters. Arctic Rev. L. Polit. 5, 201-226.

Latour, B. (1987). Cience in Action: How to Follow Scientists and Engineers through Society. 11. Cambridge, Mass: Harvard Univ. Press.

Latour, B. (2004). Politics of Nature: How to Bring the Sciences into Democracy. Cambridge, Mass: Harvard University Press.

Law, J. (2004). After Method: Mess in Social Science Research. International Library of Sociology Routledge: Routledge, London.

Lemos, M. C., Arnott, J. C., Ardoin, N. M., Baja, K., Bednarek, A. T., Dewulf, A., et al. (2018). Art Dewulf, Clare Fieseler, et al.To Co-Produce or Not to CoProduce. Nat. Sustain. 1 (12), 722-724. doi:10.1038/s41893-018-0191-0

Liebenberg, L., Steventon, J., Brahman, N., Benadie, K., Minye, J., Langwane, H., et al. (2017). Smartphone Icon User Interface Design for Non-literate Trackers and its Implications for an Inclusive Citizen Science. Biol. Conservation 208 (April), 155-162. doi:10.1016/j.biocon.2016.04.033

Lövbrand, E. (2011). Co-Producing European Climate Science and Policy: A Cautionary Note on the Making of Useful Knowledge. Sci. Pub. Pol. 38 (3), 225-236. doi:10.3152/030234211X12924093660516

Lövbrand, E., Pielke, R., and Beck, S. (2011). A Democracy Paradox in Studies of Science and Technology. Sci. Technol. Hum. Values 36 (4), 474-496. doi:10.1177/0162243910366154

McNie, E. C., Parris, A., and Sarewitz, D. (2016). Improving the Public Value of Science: A Typology to Inform Discussion, Design and Implementation of Research. Res. Pol. 45 (4), 884-895. doi:10.1016/j.respol.2016.01.004

Meadowcroft, J. (2004). “"Deliberative Democracy.” in Environmental Governance Reconsidered: Challenges, Choices, and Opportunities," in Rosemary O'Leary. American and Comparative Environmental Policy. Editors R. F. Durant and D. J. Fiorino (Cambridge, Mass: MIT Press).

Monahan, T., and Fisher, J. A. (2010). Benefits of 'observer Effects': Lessons from the Field. Qual. Res. 10 (3), 357-376. doi:10.1177/1468794110362874

Mouffe, Cl. (2000). The Democratic Paradox. London; New York: Verso.

Nogueira, L. A., and Nogueira, T. F. (2015). “Exploring Ethics in Innovation," in In Handbook of Research on Business Ethics and Corporate Responsibilities. Editors D. E. Palmer (Hershey, USA: Advances in Business Strategy and Competitive AdvantageIGI Global), 56-90. doi:10.4018/978-1-4666-7476-9.ch004
Norström, A. V., Cvitanovic, C., West, S., Wyborn, C., Balvanera, P., Bednarek, A. T., et al. (2020). Principles for Knowledge Co-production in Sustainability Research. Nat. Sustain. 3, 182-190. doi:10.1038/s41893-019-0448-2

Oreskes, N., and Conway, E. M. (2010). Merchants of Doubt: How a Handful of Scientists Obscured the Truth on Issues from Tobacco Smoke to Global Warming. 1st U. New York: Bloomsbury Press.

Owen, R., Pansera, M., Macnaghten, P., and Randles, S. (2021). Organisational Institutionalisation of Responsible Innovation. Res. Pol. 50 (1), 104132. doi:10.1016/j.respol.2020.104132

Parry, R. (2020). "Epistêmê and Technê.," in The Stanford Encyclopedia of Philosophy. Editor E. N. Zalta (Summer 2020. Metaphysics Research Lab, Stanford University). Available at: https://plato.stanford.edu/archives/ sum2020/entries/episteme-techne/.

Pereira, M. A., and au, J. R. (2020). Beyond the Co-production of Technology and Society: The Discursive Treatment of Technology with Regard to Near-Term and Long-Term Environmental Goals. Techn. Soc. 61 (May), 101244. doi:10.1016/j.techsoc.2020.101244

Pløger, J. (2004). Strife: Urban Planning and Agonism. Plann. Theor. 3 (1), 71-92. doi:10.1177/1473095204042318

Poblet, M., Casanovas, P., and Rodríguez-Doncel, V. (2019). "Deliberative and Epistemic Approaches to Democracy," in In Linked Democracy: Foundations, Tools, and Applications. Editors Marta. Poblet, P. Casanovas, and V. RodríguezDoncel (Cham: Springer Briefs in LawSpringer International Publishing), 27-49. doi:10.1007/978-3-030-13363-4_2

Poli, R. (2014). Anticipation: A New Thread for the Human and Social Sciences? Soc. Sci. 2 (3), 14.

Polk, M. (20152004-2014). Transdisciplinary Co-production: Designing and Testing a Transdisciplinary Research Framework for Societal Problem Solving. Futures 65 (January), 110-122. doi:10.1016/j.futures.2014.11.001

Porter, L. (2011). The Point Is to Change it. Plann. Theor. Pract. 12 (4), 477-480. doi:10.1080/14649357.2011.626296

Röhrs, J., Dagestad, K-F., Strand, K. O, Grøsvik, B. E., and Mauritzen, C., (2020). "Backtracing of Marine Litter and Microplastic from OSPAR Beaches in the North Atlantic.Oslo, Norway: European Geosciences Union. EGU2020-5977. doi:10.5194/egusphere-egu2020-5977

Rau, H., Goggins, G., and Fahy, F. (2018). From Invisibility to Impact: Recognising the Scientific and Societal Relevance of Interdisciplinary Sustainability Research. Res. Pol. 47 (1), 266-276. doi:10.1016/j.respol.2017.11.005

Ravetz, J., and Funtowicz, S. (1999). "Post-Normal Science An Insight Now Maturing. Futures 6, 641-646.

Ravetz, J. (1971). Scientific Knowledge and its Social Problems. New Brunswick, N.J: Transaction Publishers.

Ravetz, J. (1999). What Is Post-Normal Science. Futures 7.

Rodríguez, H., Fisher, E., and Schuurbiers, D. (2013). Integrating Science and Society in European Framework Programmes: Trends in Project-Level Solicitations. Res. Pol. 42 (5), 1126-1137. doi:10.1016/j.respol.2013.02.006

Rosendahl, J., Zanella, M. A., Rist, S., and Weigelt, J. (20152004-2014). Scientists' Situated Knowledge: Strong Objectivity in Transdisciplinarity. Futures 65 (January), 17-27. doi:10.1016/j.futures.2014.10.011

Rovdata and Naturvårdsverket (2021). Skandobs. 2021. Available at: https://www. skandobs.no.

Rowe, G., and Frewer, L. J. (2004). Evaluating Public-Participation Exercises: A Research Agenda. Sci. Technol. Hum. Values 29 (4), 512-556. doi:10.1177/ 0162243903259197

Rybråten, S., Bjørkan, M., Hovelsrud, G. K., and Kaltenborn, B. P. (2018). Sustainable Coasts? Perceptions of Change and Livelihood Vulnerability in Nordland, Norway. Local Environ. 23 (12), 1156-1171. doi:10.1080/ 13549839.2018.1533931

Saltelli, A., and Funtowicz, S. (2017). What Is Science's Crisis Really about? Futures 91 (August), 5-11. doi:10.1016/j.futures.2017.05.010

Saltelli, A., and Giampietro, M. (2017). What Is Wrong with Evidence Based Policy, and How Can it Be Improved? Futures 91 (August), 62-71. doi:10.1016/ j.futures.2016.11.012

Scherhaufer, P. (2021). Better Research through More Participation? the Future of Integrated Climate Change Assessments. Futures 125 (January), 102661. doi:10.1016/j.futures.2020.102661

Scott, D. (2016). Framing and Responding to Scientific Uncertainties. Biofuels Synth. Biol. Convention Biol. Divers. 16, $245-260$. 
S. Jasanoff and S-H. Kim (Editors) (2015). Dreamscapes of Modernity: Sociotechnical Imaginaries and the Fabrication of Power (Chicago; London: The University of Chicago Press).

S. Jasanoff (Editors) (2004). Tates of Knowledge: The Co-production of Scienceand Social Ord (London: International Library of SociologyRoutledge).

Silver, J. J., and Campbell., L. M. (2005). Fisher Participation in Research: Dilemmas with the Use of Fisher Knowledge. Ocean Coastal Manage. 48 (9), 721-741. doi:10.1016/j.ocecoaman.2005.06.003

Skolnikoff, E. B. (2001). The Political Role of Scientific Cooperation. Techn. Soc. 23 (3), 461-471. doi:10.1016/S0160-791X(01)00026-4

Stoffle, R. W., Sittler, C., Van Vlack, Kn., Pickering, E., Heather, H., and Lim, H. (2020). Living Universe or GeoFacts: Stone Arches in Utah National Parks Epistemological Divides in Heritage Environmental Communication. Int. J. Intangible Heritage 15, 16-27.

Strand, K. O., Huserbråten, M., Dagestad, K-F., Mauritzen, C., Grøsvik, B. E., Nogueira, L. A., et al. (2021). "Potential Sources of Marine Plastic from Survey Beaches in the Arctic and Northeast Atlantic. Sci. Total Environ.

Strand, R., and Oughton, D. (2009). Risk and Uncertainty as a Research Ethics Challenge. Oslo, Norway: The National Committee for Research Ethics in Science and Technology (NENT).

Turner, S. P. (2015). "Social Scientists as Experts and Public Intellectuals," in International Encyclopedia of the Social \& Behavioral Sciences. Editor J. D. Wright. Second Edition (Oxford: Elsevier), 695-700. doi:10.1016/B9780-08-097086-8.03009-9

Turnpenny, J., Jones, M., and Lorenzoni, I. (2011). Where Now for Post-Normal Science?: A Critical Review of its Development, Definitions, and Uses. Sci. Technol. Hum. Values 36 (3), 287-306. doi:10.1177/0162243910385789

Van de Ven, A. H. (2007). Engaged Scholarship: A Guide for Organizational and Social Research. Cambridge, UK: Oxford University Press.
Villarrubia-Gómez, P., Cornell, S. E., and Fabres, J. (2018). Marine Plastic Pollution as a Planetary Boundary Threat - the Drifting Piece in the Sustainability Puzzle. Mar. Pol. 96 (October), 213-220. doi:10.1016/j.marpol.2017.11.035

Wildschut, D. (2017). The Need for Citizen Science in the Transition to a Sustainable Peer-To-Peer-Society. Futures 91 (August), 46-52. doi:10.1016/ j.futures.2016.11.010

Williams, R., and Edge, D. (1996). The Social Shaping of Technology. Res. Pol. 25 (6), 865-899. doi:10.1016/0048-7333(96)00885-2

Wilson, P. (1983). Second-Hand Knowledge: An Inquiry into Cognitive Authority Contributions in Librarianship and Information Science, 44. Westport, Conn: Greenwood Press.

Conflict of Interest: The authors declare that the research was conducted in the absence of any commercial or financial relationships that could be construed as a potential conflict of interest.

Publisher's Note: All claims expressed in this article are solely those of the authors and do not necessarily represent those of their affiliated organizations, or those of the publisher, the editors and the reviewers. Any product that may be evaluated in this article, or claim that may be made by its manufacturer, is not guaranteed or endorsed by the publisher.

Copyright (c) 2021 Nogueira, Bjørkan and Dale. This is an open-access article distributed under the terms of the Creative Commons Attribution License (CC BY). The use, distribution or reproduction in other forums is permitted, provided the original author(s) and the copyright owner(s) are credited and that the original publication in this journal is cited, in accordance with accepted academic practice. No use, distribution or reproduction is permitted which does not comply with these terms. 